\title{
A Contabilidade e a Teoria da Informação
}

\author{
Autor: Antonio Zoratto Sanvicente \\ Professor Titular em Teoria da Administração Financeira da Faculdade de Economia e \\ Administração da Universidade de São Paulo.
}

Revisão feita em fevereiro de 1990

Agradeço as sugestões feitas pelo Prof. Sergio de ludicibus, que permitiram investigar novos aspectos da questão que julgo terem enriquecido o trabalho.

\section{Introdução}

A proposta de criação de um indexado específico a cada empresa, tendo em vista ajustar os seus resultados operacionais segundo as peculiaridades dessa empresa, feita em Fama (1986), pode ser incluídas na terminologia de Demski e Feltham (1976), como um exemplo do problema de escolha entre alternativas de mensuração.

Tendo em vista algumas afirmações feitas no texto apresentado pelo autor da proposta na palestra que proferiu no IV Encontro Annual de Executivos Financeiros (Fama) (1987), tais como por exemplo, as de que, sob inflação, o Lucro passa a ser apenas um valor nominal sem guardar relação real com os itens que the deram origem (p.2) e que é portanto preciso "ajustar o lucro minimolidade" (p.2), é importante lembrar que esse tipo de preposição representa apenas um dos enfoques com os quais tem se desenvolvido o pensamento em contabilidade, bem como salientar, que há outros aspectos, ignorados na proposta, que não poderiam justificar esse tipo de afirmação, de acordo com o enfoque mais completo e moderno do que a informação contábil.

Segundo de Demski Feltham, a literatura contábil está repleta de exposições sobre prós e contras de método específicos de mensuração de custos e resultados; exemplos são as discussões sobre o custeio direto e custeio por absorção, as maneiras de medir ativos para o cálculo da taxa de retorno sobre 0 investimento (ROI), a fixação de preços de transferência entre unidades de uma 
mesma empresa, e métodos alternativos de alocação ou rateio de despesas gerais a produtos ou centros de custo.

Entretanto, segundo esses autores, essa literatura não havia desenvolvido, a época em que sua obra foi publicada, uma base conceitual para a escolha entre alternativas de mensuração. Para estes autores existe um enfoque que preenche essa lacuna: fazer a escolha entre as alternativas a partir de uma análise apoiada na teoria econômica, e encarada como uma decisão. Tal como na teoria do consumidor, o que é melhor depende de oportunidade, preferências e expectativas. Neste caso, o Objeto de escolha é a informação, e é preciso considerar todos os recursos consumidos em sua obtenção. Assim sendo, a escolha deve ser feita com base no impacto esperado de medidas alternativas de custo sobre os resultados das ações selecionadas pelos usuários dessas medidas. Os autores afirmam que não se trata de um enfoque revolucionário, mas que apresenta como vantagem reconhecer formalmente o problema de escolha de informação enfrentado pelo contador ou pelo "Controller".

\section{II - Três enfoques Básicos}

Para Demski e Feltham, há três enfoques gerais que tem tido impacto importante sobre a evolução do pensamento em Contabilidade, os quais possamos explicar, mantendo seus títulos no original.

1) "Historical Communication"

Este enfoque apóia-se na crença de que é possível estabelecer um conjunto único de regras e coleta de processamento de dados que permite que os dados resultantes sejam compreendidos por qualquer usuário. Assim caberia ao usuário fazer os ajustes, nos dados que recebesse, para atender seus fins específicos. A decorrência lógica deste enfoque é o desenvolvimento de padrões e princípios de contabilidade, implicitamente baseada no conceito de verdade absoluta, sendo a principal tarefa do contador "escolher o procedimento de mensuração que identifica o custo verdadeiro, ou pelo menos dele se aproxima(Demski e Feltham, p.5)".

Nos trabalhos apresentados por Fama, acima citados encontramos exemplos dessa posição, como também já foi reproduzido acima. Outros casos encontramse no texto de sua palestra: usando a técnica por ele proposta, "obtém-se um (a) medida do desempenho real da empresa" (Fama, 1987, p.8) (nossa ênfase).

Isso não quer dizer que algumas obras muito conhecidas, recentes, e outras nem tão recentes assim, não reflitam posição semelhante. Como exemplo do segundo caso, citamos o utilizadíssimo manual de Horngren (1972, p. 313): A aceitação do custeio direto para fins de publicações externa e demonstrativos não deve ser a questão mais importante para contadores e administradores. 
Os sistemas de uma empresa permitem o uso de qualquer um dos métodos; o ponto importante é que os relatórios internos devem usar o enfoque de contribuição, isto é, o custeio direto com a técnica de avaliação e controle. (nossa ênfase)

Já como exemplo de obra mais recente, o que esta exercendo uma influência muito grande sobre os estudiosos desta área podemos citar Johnson e Kaplan (1987). Esses autores propõem um re-exame da Contabilidade Gerencial para que "Decisões possam ser tomadas com a melhor informação possível" (p.4), e mais adiante criticamos sistemas atuais de informações contábeis para fins de gestão dizendo, entre outras coisas, que neles "o custeio de produtos é distorcido" (p.13), o que pressupõe, obviamente, a existência de um custeio "correto" (nossa ênfase, acima)

2) "User decision model"

Neste segundo enfoque, parte-se da identificação das decisões a serem tomadas (por exemplo: investimento, fixação de preços, volume de operação). É reconhecida a possibilidade de que modelos diferentes de decisão conduzam à necessidade de geração de dados distintos. O desenvolvimento do "management Accounting", particularmente o custeio direto, decorreu desta idéia, e é o seu estado atual que é criticado por Johnson e Kaplan. Esse enfoque teve uma contribuição importante porque refletiu um reconhecimento de que há diferenças entre usuários.

Entretanto, os dois enfoques anteriores têm, segundo Demski e Feltham , Três defeitos básicos:

a) a verdade não pode ser obtida a custo zero, ou seja, toda mensuração consome recursos, "portanto, qualquer teoria de mensuração de custos deve ter como componente o custo de mensuração". (pp.7-8) para Demski e Feltham, os dois enfoques anteriores consideram custos e benefícios implicitamente. Assim, [para o enfoque de "historical communication", não vale a pena diferenciar entre usuários; para o enfoque do "user decision model", vale a pena faze-lo. O problema é que neste enfoques isso não é feito explicitamente. Por isso eles são incapazes de explicar porque um método de custeio escolhido, e não outro, e muito menos indicar que considerações deveriam ser feitos a se avaliar a viabilidade de substituir um método de mensuração de custos ou ressaltados por outro].

b) Como os usuários de informação operam sob incerteza, o reconhecimento deste fato põe em cheque o conceito de "custo verdadeiro" ou "custo real", já que ele implicitamente pressupõe um ambiente de certeza.

c) Para pessoas diferentes, com preferências distintas, as reações a medidas específicas também podem ser diferentes. Como exemplo, citam a

Cadernos de Estudos n ${ }^{\circ}$ 02, São Paulo, FIPECAFI - Abril/1990 
possibilidade de distorção internacional de padrões de custo numa empresa, quando um gerente comunica padrões a um subordinado. Para o gerente, eles são razoáveis, mas para o subordinado, são "apertados" em demasia. Portanto, poder-se-ia falar em dois "custos verdadeiros".

Demski e Feltham propõem um terceiro enfoque:

\section{3) "Information evaluation"}

Segundo este enfoque, maneiras diferentes de medir custos ou resultados são preferíveis na medida em que produzem resultados mais desejáveis do que os recursos que consomem. Por exemplo, dizem que "um sistema de mensuração que distorce sistematicamente o saldo de caixa de uma empresa pode ser desejável, dependendo da aplicação a que se destinam os dados e do custo de produção de medidas mais precisas".(p.8)

\section{III- Ilustração: “Information Evaluation”}

Para fixar melhor as idéias, reproduzimos abaixo, de maneira resumida, o exemplo apresentado por Demski e Feltham para explicar o enfoque que propõe.

Exemplo: Imagine-se o caso de uma empresa à qual é feita uma encomenda especial, de 1000 unidades de um produto, ao preço unitário de \$20. A encomenda é dita especial no sentido de que não se repetirá e não interferirá com as vendas atuais e futuras da empresa.

Os custos estão assim estimados:

Matéria prima: $\$ 5000$

Uso de mão-de-obra direta: 800 horas no departamento $A$

200 horas no departamento B

A encomenda só será aceita se tiver margem de contribuição esperada e positiva, ou seja, se o incremento esperado de custos de mão-de-obra direta de despesas gerais for inferior a $\$ 15.000$, ou seja, incremento de receita menos incremento de custos de matéria prima.

No sistema de mensuração de custos atualmente usado pela empresa, a alocação de custos de mão-de-obra direta e despesa geral variáveis aos produtos é feita segundo a taxa média, calculada para toda a fabrica. No período mais recente, essa taxa foi de $\$ 16$ por hora de mão-de-obra direta.

Portanto, nas condições presentes, a margem de contribuição esperada é: $\$ 20.000-\$ \$ 16(800+200)=-\$ 1.000$, e a encomenda deveria ser rejeitada. 
Suponhamos, porém, que seja feita uma análise para calcular novamente as taxas de alocação. Ou seja, que alguém proponha um sistema supostamente "melhor", mais preciso, ou real, o que o enfoque de "information evaluation", sendo atualmente explicado, pretende indicar é que, a pergunta apropriada, neste momento, é: deve ser feita a análise e devem ser fornecidos os seus resultados a que vai tomar a decisão? A atitude correta não é: indiscutível que devemos usar o novo sistema, afinal, ele é "melhor"!

Imaginemos que o contador suponha que a análise uma vez feita, apresente uns dos três resultados possíveis indicados a seguir:

\begin{tabular}{lcr}
\hline $\begin{array}{l}\text { Evento } \\
\text { para depto. B }\end{array}$ & Taxa para depto. A & Taxa \\
\hline 1 & $\$ 12$ & $\$$ \\
20 & & 14 \\
18 & & 16 \\
$3{ }^{3}$ & & \\
\hline
\end{tabular}

Como pode ser observado, o terceiro evento significa: "Foi feita uma nova análise e se confirmou a média que já utilizávamos".

Para uso posterior, imaginemos que os três eventos tenham as seguintes probabilidades: 0,2,0,2 e 0,6, respectivamente.

Com os dados acima, os resultados possíveis passariam a ser:

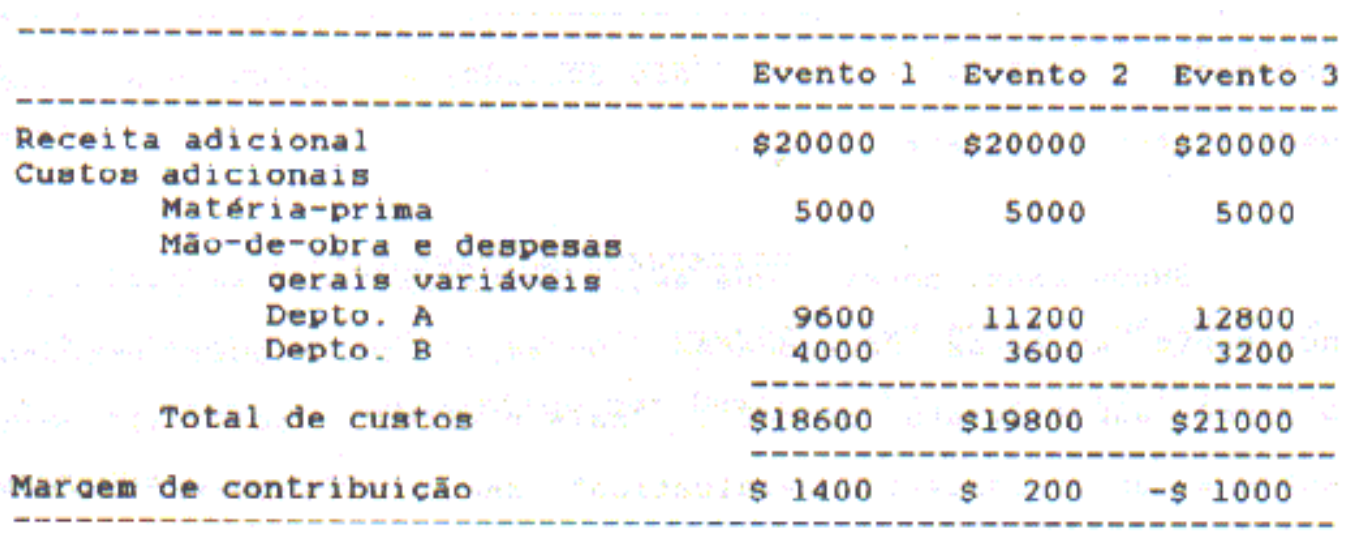

Supomos que o responsável pela decisão em relação à encomenda, conhecendo os resultados da análise, os une na tomada de decisão. Portanto, a encomenda só será aceita pela empresa se a análise produzir a informação de que as taxas são iguais a $\$ 12$ e $\$ 20$, ou $\$ 14$ e $\$ 18$ (isto é, se a realidade for diferente do que se conhece antes da implantação do novo método de mensuração). 
Para o contador cujo problema é decidir entre dois sistemas de estimação de taxas (uma decisão muito diferente, e anterior, portanto, a que foi exposta no parágrafo procedente), há duas alternativas:

A) Não mudar o sistema de mensuração, com resultado adicional, para a empresa, igual a $\$ 0$;

B) Fazer a substituição pelo novo sistema, "real", com ganho adiciona de $\$ 1.400$, $\$ 200$, ou $\$ 0$ (no terceiro evento, como nos demais, o usuário da informação obtida - isto é, se ocorrerem os eventos 1 ou 2, a encomenda é aceita, e se ocorre o evento 3, como resultado da análise, a encomenda não é aceita) menos o custo da análise.

Como escolher? Tudo depende de preferências (racionalidade e aversão a risco), expectativas quanto à possibilidade de ocorrência de cada evento, e do custo da análise (representado a baixo por C_).

Suponho que as preferências sejam expressas por neutralidade em relação ao risco, e com as probabilidades acima fornecidas, temos:

Margem de Contribuição esperada=

$$
0,2(\$ 1.400)+0,2(\$ 200)+0,6(\$ 0)-C=\$ 320-C
$$

Assim, a análise (mudança de sistema de mensuração) só valeria a pena se $\mathrm{C}<$ $\$ 320$.

Em outras palavras, SE O CUSTO DA ANÁLISE FOR SUPERIOR A \$320, NÃO VALERÁ A PENA USAR UM SISTEMA DE MENSURAÇÃO SUPOSTAMENTE "MAIS CORRETO" OU "REAL".

\section{Considerações sobre o custo da informação}

Uma possível critica ao enfoque acima exemplificando seria a de que, na prática, isto é, em situações mais próximas da realidade, é muito difícil estimar o custo da informação. Isso, porém, não é correto.

O que foi visto neste exemplo é uma aplicação da idéia de calculo do "valor esperado da informação imperfeita" (Ver Hollowey 1979), para uma apresentação completa, e Foster (1978, cap. 1), (e para uma aplicação a um problema na área de contabilidade). A sua principal vantagem é permitir que se determine formalmente o benefício marginal de novas informações, e se fixe o custo máximo que estaríamos dispostos a pagar pelas novas informações (custo marginal).

Nesse sentido, a parte mais complexa da análise não é o calculo do custo da informação, e sim o calculo dos benefícios, mas é justamente para isso que se usa 
a "teoria da decisão" para se ter uma noção do que seria possível para chegar a um calculo do custo de um novo sistema de informações, basta ver o texto as paginas 147-148 de Fama (1986), para se perceber que poderia orçar as diversas atividades ali previsíveis:

"No caso das sociedades pesquisadas, analisaram-se os resultados de cerca de 3.600 notas fiscais de recebimento e cerca de 6.400 notas fiscais de vendas, recebidas e emitidas mensalmente em empresas que possuem, em média, 3.640 funcionários, 56 tipos de linha de produto e cerca de 60 tipos principais de matérias primas".

O volumo do processamento necessário para esses dados de entrada poderia ser estimado facilmente através das análises exigidas, do tempo de digitação, e de velocidade com a qual a unidade central de processamento de dados produziria o numeroso índice aí proposto. (É preciso lembrar que esse levantamento destinouse não apenas a eventual utilização regular do indexador interno, mas principalmente ao seu desenvolvimento inicial para a sua implantação).

E tampouco é única a idéia de comparar custos e benefícios de índices diferentes de preços através da "teoria da decisão". Para comprovar isso, veja-se o artigo de Shriver (1986), no qual, em resposta a uma solicitação do Financial Accounting Standards Board, e para avaliar a "Confiabilidade dos dados exigidos pelo statement 33", São apresentadas evidências sobre a precisão de diferentes índices para a estimação de custos correntes de máquinas e equipamentos.

Uma das conclusões desse artigo é bastante relevante ao contexto da presente discussão: "os índices mais específicos nem sempre resultam em precisão maior do que índices mais agregados".(p.162)

Compare-se essa conclusão de uma análise quantitativa extensiva com a opinião expressa em Fama (1986, p.5): O índice de variação do valor da ORTN, assim como qualquer outro índice genérico da economia (sic), tais como IGP, INPC, taxa de variação cambial, etc. mantém a grande restrição de não especificidade da própria empresa ".(nossa ênfase)".

A essa altura, espero que o leitor já tenha compreendido que a palavra restrição é imprópria, quando se discute o papel do dado contábil do ponto de vista da teoria da informação: o índice tem valor (seu beneficio marginal é superior ao seu custo marginal) ou não o tem, e pode muito bem acontecer que esta relação seja mais favorável para um índice "genérico" do que para um índice "especifico", ou ainda, como mostra Shriver, que um índice genérico pode levar as melhores previsões do que índices específicos.

EM RESUMO, É IMPORTANTE PARA AQUELES QUE SE PREOCUPAM COM A "PRATICA" QUE NÃO PODEMOS FUGIR A UMA QUANTIFICAÇÃO DE CUSTOS E BENEFICIOS: O "teórico" E INACEITAVEL São FICAR LIMITADOS A 
ARGUMENTER QUE NOVAS INFORMAÇÕES DEVEM SER OBTIDAS PORQUE SÃO "MELHORES" OU MAIS "CORRETAS".

\section{v. Evidencias Sobre A Utilidade de Informações Alternativas para os Investidores no Mercado de Capitais.}

Devido à falta de pesquisa sobre a reação do publico a divulgação de informações contábeis e financeiras no mercado brasileiro de ações, nada pode ser afirmado ainda sobres à utilidade de métodos diferentes de ajuste de demonstrativos em função de inflação.

E é justamente por isso que é de estranhar que se introduziu, pela instrução CVM numero 64, de 19 de maio de 1987, o método de correção integral com a intenção de homogeneizar a publicação de resultados, com a declarada finalidade de aprimora-la (torna-la melhor, na linguagem deste trabalho).

Essa intenção fica clara no texto da Nota Explicativa à Introdução que diz ter havido uma preocupação "Com a evolução qualitativa das demonstrações financeiras", já apontando acima, que nada tem a ver com o valor da informação que esta sendo produzida.

Voltando a questão da "utilidade" das informações sobre o efeito da inflação nas empresas, podemos citar os resultados comentados em Griffin (1982): "Com base em numerosas pesquisas, demonstrações suplementares sobre custos de reposição de ativos ou avaliação de despesas a valores correntes parece não ter tido impacto significativo sobre retornos em títulos".(p.191). Isso quer dizer na verdade, que sua publicação, em função do FAZ 33 ("financial reportin and changing prices"), pareceu não fornecer novas informações ao mercado, o que não quer dizer que seja relevante, pois poderia ter sido obtida de outra maneira: $O$ "sistema FAZ 33", isto sim, é que não tinha conteúdo internacional. Prosseguido, Griffin diz que esses resultados (a irrelevância do FAZ 33) foram verificados "apesar da queda óbvia e às vezes dramática sofrida pela taxa de retorno contábil resultante de transformação de lucros baseados em custo histórico para o uso de custo corrente ou custo de reposição". (pág.191)

Em função de sua reduzida informatividade, o que era preconizado pelo FAZ 33 veio a desaparecer virtualmente em 1986, com o FAZ 89. Em vigor desde 2 de Dezembro de 1986, essa nova norma suplantou, não só a de № 33, como suas adaptações e complementações: FAZ 39, 40, 41, 46, 54, 69, 70 e 82.

Por quatro votos a três, o FASB tornou voluntária a divulgação suplementar de informações a custo corrente e poder aquisitivo constante, e isso em conseqüência de um experimento que havia durado cinco anos. 
Conforme a revista FORBES (1ำ de Junho de 1987), inicialmente, a década de 1970, as grandes empresas haviam resistido à introdução de alguma fórmula de ajuste pela inflação porque temiam que qualquer formula de ajuste resultasse em informações sem utilidade e levasse a custos maiores.

É importante lembrar que o FAZ 33 exigia a determinação de custos correntes, levando a investigação dos preços de ativos e tecnologias ao nível do estado da arte, e não uma simples indexação de custos históricos (seja por um índice oficial comum ou por um indexador específico), e portanto, era um sistema relativamente caro. Em que pese essa diferença importante, não deixa de ser interessante observar como os aspectos básicos da discussão aparentemente preocupados com os aspectos práticos do problema, conforma as ênfases feitas no parágrafo anterior.

Por fim, e por motivos de coerência, é preciso não esquecer de uma questão empírica crucial, que ainda sequer começamos a estudar, é do possível impacto, sobre preços de mercado de valores imobiliários, da divulgação de demonstrações financeiras ajustadas a variação de preços no Brasil. É possível que esse impacto seja substancial (ou não), e que assim esse estudo não for feito, não é recomendável afirmar que o ajuste contribui com algo de significado.

É provável que esses ajustes sejam tão mais informativos quanto menor for a correlação entre valores correntes e valores históricos nas demonstrações financeiras de uma dada empresa. Caso contrário (se a correlação fosse elevada), a informação equivalente poderia ser conseguida com a serie de valores históricos. E ai é plausível que essa informatividade não dependa, necessariamente, do nível de taxa de inflação. 
VI. BIBLIOGRAEIA

Demski, J.S., e Feltham, G.A., Cost Determination: A Conceptual Approach. Iowa Sate University Press, Ames, Iowa, 1976.

Famá, R., "Análise do Desempenho Operacional das Empresas com a Utilização de Números-fndices: um Estudo num Conglomerado Empresarial". Tese de doutorado, Faculdade de Economia e Administração da Universıdade de São Paulo, 1986.

Famá, R., "Indexador Interno das Empresas vrsus OTN e Dolar". Palestra proferida no IV Encontro Anual dos Executivos Financeiros, em 24 de agosto de 1987.

Foster, G., Elmancial statement Analyais. Prentice-Hall, Englewood Cliffs, NJ, 1978 .

Griffin, P.A., "Usefulness to Investors and creditors of Information Provided by Financial Reporting". Financial Accounting Standards Board Research Report, stamford, CT, 1982 .

Holloway, C.A., Decision Makino Under Uncertainty: Models and Choices. Prentice-Hall, Englewood Cliffs, NJ, 1979.

Horngren, C.T., Cost Accounting, terceira edicão. PrenticeHall, Englewood Cliffs, NJ, 1972.

Johnson, H.T., e Kaplan, R.S., Relevance Loat: The Rise and Fil of Managment Accounting. Harvard Business School Press, Boston, MA, 1987. 


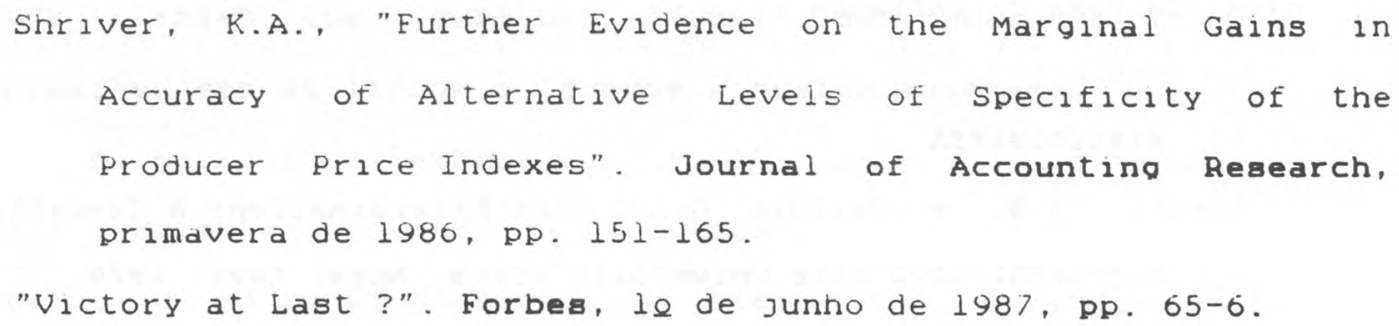

